\title{
Gestão acadêmica - complexidade e integração
}

\author{
Uma universidade que pretenda fazer frente às novas demandas \\ do conhecimento, ampliando suas formas de atuação na sociedade, \\ deve criar condições para que todos os sujeitos compreendam a \\ realidade cultural, social, política e econômica do país.
}

\author{
Elza Maria Neffa Vieira de Castro*
}

* Doutora em Desenvolvimento, Agricultura e Sociedade. Coordenadora Geral do Projeto de Educação Ambiental do Programa de Despoluição da Baía de Guanabara - PEA/PDBG. Núcleo de Referência em Educação Ambiental da Faculdade de Educação - UERJ.

A o pensar em gestão acadêmica refletimos sobre a complexidade do tema e sobre a necessidade de se compreender o contexto em que o ser humano contemporâneo se insere para que possamos tecer algumas considerações.

Falar de complexidade remete-nos a Edgar Morin que combate a simplificação do pensamento por esse não exprimir a unidade e a diversidade presentes no todo.

Sua proposta de reformar o pensamento baseia-se na valorização do complexo e na defesa da interligação de todos os conhecimentos como forma de se obter uma visão geral da realidade, uma perspectiva global que favorece a aprendizagem.

Sob a ótica da Teoria da Complexidade, a sala de aula aparece como um fenômeno complexo que abriga uma diversidade de ânimos, culturas, classes sociais e econômicas, sentimentos etc. Por isso, constitui-se como um espaço heterogêneo ideal para se dar início a uma reforma da mentalidade, necessária à superação da especialização que fragmenta o currículo escolar em disciplinas estanques e não complementares.

A percepção do conjunto surge, para Morin, da busca do aluno para estabelecer relações e favorece o ensino ao possibilitar a incorporação dos problemas cotidianos ao currículo, contextualizando-o.

\section{CARACTERÍsticas da MOdERNIDADE}

A realidade dinâmica, complexa e incerta, vivenciada pelos seres humanos neste momento de transição milenar, demanda uma reflexão sobre os valores ensejados pela modernidade, entendida como um conjunto de experiências vitais, compartilhado por homens e mulheres, de espaço e tempo, de si mesmo e dos outros, das possibilidades e perigos da vida, registradas ao longo dos últimos anos, que despejou a todos num turbilhão de permanente desintegração e mudança de luta e contradição, de ambigüidade e angústia.

A modernidade caracterizou-se por estilos de vida que desvencilharam os homens de todos os tipos tradicionais de ordem social, de uma maneira nunca vista anteriormente. A transformação acelerada da paisagem européia e, posteriormente, de todo o planeta é percebida:

- por inúmeros fenômenos que configuram uma situação particular nas formações sociais, inicialmente no século XVI² com a sedimentação do sistema capitalista comercial e, primordialmente,

1. Marshall Berman. Tudo que sólido desmancha no ar: a aventura da modernidade. São Paulo : Companhia das Letras, 1996.

2. Krisham Kumar enfatiza a importância do capitalismo comercial no século XVI no processo de gestação e nascimento da modernidade. Para este autor, a modernidade relaciona-se mais estreitamente com o capitalismo do que propriamente com o industrialismo. Esse fato deve-se às formas de vida econômica da sociedade pós-industrial à pós-moderna. Da sociedade pós-industrial à pós-moderna: novas teorias sobre o mundo contemporâneo. Rio de Janeiro : Jorge Zahar, 1997. 
nos séculos XVII e XVIII ${ }^{3}$ quando é conformada por descobertas físicas que mudaram a visão de homem e de mundo;

- por uma enorme concentração de populações em centros urbanos;

- pelo crescimento exorbitante da produtividade manufatureira e, mais tarde industrial, geradora de riqueza concentrada em contraste com o aumento da pobreza;

- pelo desenvolvimento das "forças de produção" com cristalização de duas classes sociais antagônicas - burguesia e operariado - em luta constante;

- pela presença de Estados nacionais burocráticos cada vez mais fortes e de conglomerados multinacionais de capital;

- por um mercado mundial, em crescente expansão, destruidor dos mercados locais e regionais;

- por movimentos sociais organizados;

- por meios de comunicação de massa integradores de espaços distantes, em tempos curtos;

- pela valorização da razão em detrimento da religião;

- por sujeitos sociais respeitados como indivíduos (e não mais referenciados através de linhagens, famílias ou clãs);

- pelo pertencimento social dado pela origem nacional;

- por desejos e reivindicações ampliados de revolução permanente, de desenvolvimento infinito, de constante criação e renovação em todas as esferas da vida.

A velocidade com que os acontecimentos ocorrem, a mutação dos valores, a degradação moral e material (corrupção), a atomização das pessoas, o anonimato, a fragmentação das idéias, a mercantilização, a reorganização espacial provocada pela desterritorialização do capital e a conseqüente criação de centros hegemônicos mais poderosos que os Estados nacionais são alguns aspectos resultantes da mundialização da economia marcada pela hegemonia das políticas neoliberais, a aceleração da produ- ção capitalista do mundo não-material e da vivência da terceira onda de revolução tecnológica ${ }^{4}$, que provocaram incertezas e indeterminações e geraram a necessidade de se

\footnotetext{
"implodir o paradigma antropocêntrico, causalista, linear e determinista para, em seu lugar, exercitar um estilo de pensamento egocêntrico e cosmológico que privilegie a síntese, a cooperação e a cumplicidade entre homens e coisas, a sabedoria intuitiva, o imaginário, o poético, enfim, o intercâmbio entre vida e idéias."
}

\section{OS PARADIGMAS CIENTÍfICOS}

Os paradigmas ${ }^{6}$ da ciência na modernidade, sustentados na filosofia de Descartes e na física newtoniana, cujas bases para chegar ao conhecimento científico fundamentavam-se no Racionalismo e no Determinismo, livres de interferências subjetivas, preconceitos e superstições, mostram-se insuficientes para conceituar as modificações ocorridas na complexa realidade contemporânea, por traduzir conhecimentos que obedecem a uma lógica mecânica, permitindo previsão e predição. Essa lógica ensinou a separar e a isolar os objetos de seus contextos, a realidade dos conhecimentos especializados, o espírito da matéria; a filosofia da ciência; o conhecimento que vem da literatura do conhecimento que vem da pesquisa científica, o sujeito do conhecimento do objeto do conhecimento.

O modelo de racionalidade científica que caracteriza o paradigma moderno:

- é contra todas as formas de dogmatismo e autoridade, provenientes dos pensamentos aristotélicos e medieval;

- desconfia das evidências da experiência imediata;

- preconiza o ser humano como "senhor e possuidor da natureza";

- propõe ascensão de um conhecimento rigoroso da natureza, a partir das idéias matemáticas que fornecem, à ciência moderna, a análise, a lógica

3. Torna-se imperioso salientar que a história da modernidade desenvolve-se desde o século XVI, ainda de forma embrionária, com os sujeitos históricos apenas começando a experimentar a vida moderna.

4. Moreira, R. J. Economia política da sustentabilidade: uma perspectiva neomarxista. In: Mundo rural e tempo presente/organizadores: Luiz Flávio Carvalho Costa, Roberto José Moreira, Regina Bruno; 1999. Rio de Janeiro, RJ : Mauad, c1999.

5. Maria da Conceição de Almeida e Edgar de Assis Carvalho. Apresentação. In: Ensaios de complexidade/coordenação de Gustavo de Castro... et al. Porto Alegre: Sulina, 1997, p. 13.

6. A noção de paradigma, adotada neste estudo, parte da concepção de Kuhn em sua obra. A estrutura das revoluções científicas, define paradigma como "o conjunto das crenças, dos valores reconhecidos e das técnicas comuns aos membros de um determinado grupo". A análise incorpora, também, a proposta de Edgar Morin que conceitua paradigma através de um enfoque relacional em que conceitos-mestres sobrepõem-se às teorias rivais sem entretanto, fazê-las desaparecer. Em sua concepção, os paradigmas são estruturas de pensamento que de modo inconscientes comandam nosso discurso. Em suas palavras "um grande paradigma (episteme, "mindscape") controla não apenas as teorias e os raciocínios, mas também o campo cognitivo, intelectual e cultural em que nascem teorias e raciocínios. Controla, além disso, a epistemologia, que controla a teoria e a prática decorrente da teoria”. In: Método IV: as idéias. Porto Alegre : Sulina, 1998b. 
da investigação e o modelo de representação da estrutura da matéria. Daí derivam duas conseqüências:

- a aferição do rigor científico pelo rigor das medições;

- a redução da complexidade.

- Supõe o Mecanicismo, embasado na física newtoniana, em que todos os fenômenos físicos estão reduzidos ao movimento de partículas materiais, causado por uma atração mútua, ou seja, pela força da gravidade, e na idéia de um mundo máquina, em que o universo material é explicado em função da organização e do movimento de suas partes, como uma máquina perfeita que poderia ser descrita objetivamente independente do observador humano e a natureza funcionando de acordo com leis físicas e matemáticas; um mundo estático e eterno a flutuar num espaço vazio; um mundo que o racionalismo cartesiano torna cognoscível por via da sua decomposição nos elementos que o constituem. Conhecer significa dividir e classificar para depois determinar relações sistemáticas entre o que se separou;

- prega o Determinismo como um conhecimento utilitário e funcional capaz de promover o domínio do real e atender aos interesses da burguesia ascendente, que pressupunha dominar o estágio final de evolução da humanidade (o estado positivo de Conte; a sociedade individual de Spencer; a solidariedade orgânica de Durkheim);

- aspira ao conhecimento científico como um conhecimento causal que pressupõe a formulação de leis, à luz de regularidades observadas, com vista a prever o comportamento futuro dos fenômenos;

- rompe com o conhecimento do senso comum, na medida em que as leis da ciência moderna são um tipo de causa formal no qual o agente (causa eficiente) e o fim das coisas (causa final) são expulsos do processo de previsão e intervenção do real;

- permite a emergência das ciências sociais, a partir da transferência da possibilidade da descoberta das leis da natureza para a possibilidade da descoberta das leis da sociedade;

- considera o conhecimento científico como modelo do conhecimento universalmente válido, negando o caráter racional das formas de conhecimento que não se pautam pelos princípios epistemológicos e pelas regras metodológicas da ciência moderna;

- postula três distinções fundamentais:
- entre conhecimento científico e conhecimento do senso comum;

- entre natureza e pessoa humana;

- entre infra-estrutura - o mundo da matéria e do econômico e superestrutura - ideológico, político, jurídico.

Os efeitos dessas separações sobre o pensamento ocidental são:

- conhecimento de nós mesmos como egos isolados existentes "dentro" dos nossos corpos;

- atribuição de valor mais elevado ao trabalho mental do que ao trabalho manual;

- habilitação às indústrias de venderem produtos que proporcionem o "corpo ideal";

- impedimento aos médicos de considerarem a dimensão psicológica das doenças e aos psicoterapeutas de lidarem com o corpo dos pacientes;

- dificuldade dos fundadores da Teoria Quântica de interpretarem as observações dos fenômenos atômicos.

- Reivindica o monopólio do conhecimento científico-social através de duas concepções consideradas antagônicas, mas que partilham da distinção natureza/ser humano:

- uma mais diretamente vinculada à epistemologia e à metodologia positivistas das ciências naturais;

- e outra, de vocação antipositivista, caldeada numa tradição filosófica complexa, fenomenológica, interacionista, mito-simbólica, existencialista, pragmática, reivindicando a especificidade do estudo da sociedade.

A primeira concepção resultou do pensamento de Einstein (1905) sobre Relatividade da Simultaneidade em que ele distingue a simultaneidade de acontecimentos presentes no mesmo lugar e a simultaneidade de acontecimentos distantes, em particular dos acontecimentos separados por distâncias astronômicas. Em relação a estes últimos, o problema lógico a resolver é o seguinte: como é que o observador estabelece a ordem temporal dos acontecimentos no espaço? Por medições da velocidade da luz, partindo do pressuposto de que não há na natureza velocidade da luz.

No entanto, ao medir a velocidade numa direção única de A a B, Einstein defronta-se com um círculo vicioso. A fim de determinar a simultaneidade dos acontecimentos distantes é necessário conhecer a velocidade, mas para medir a velocidade é preciso conhecer a simultaneidade dos acontecimentos.

Einstein rompe com esse círculo, demonstrando 
que a simultaneidade dos acontecimentos distantes não pode ser verificada, pode tão só ser definida. É arbitrária e daí não poder haver contradições nos resultados quando se faz medições, uma vez que eles devolverão a simultaneidade introduzida por definição no sistema de medição.

Essa teoria veio revolucionar a noção de espaço e tempo. Não havendo simultaneidade universal, o tempo e o espaço absolutos de Newton deixam de existir e deixam transparecer a proposição de que dois acontecimentos simultâneos num sistema de referência não são simultâneos em outro sistema de referência.

- Com a equação $\mathrm{E}=\mathrm{mc}^{2}$, Einstein provou não existir distinção entre matéria e energia. Massa é energia, energia possui massa.

- Contribuiu para a descrição dos fenômenos da natureza e para o reconhecimento das partículas subatômicas como padrões de energia, trazendo a idéia da existência de um dinamismo intrínseco a essas partículas.

- O mundo passou a ser concebido como movimento, fluxo de energia e processo de mudança.

- O universo passou a ser composto de espaço/energia indissociáveis.

A Teoria Quântica (1900), de Max Planck, é a tentativa mais completa de desenvolvimento de uma abordagem global do funcionamento das leis do universo relacionadas à matéria e ao seu desenvolvimento. Introduziu o conceito de átomos de energia ou quantum.

A Teoria da Relatividade e a Teoria Quântica contribuíram para a revolução paradigmática que superou:

- a noção de espaço e tempo absolutas;

- a noção de partículas sólidas elementares;

- a objetividade científica;

- a causalidade;

- a separatividade.

A Lei da Complementaridade, introduzida por Niels Bohr, esclarece que as unidades subatômicas podem aparecer tanto como ondas ou como partículas e tudo isto, simultaneamente.

- Como partícula é um objeto físico, concreto e tem massa, ocupa um lugar no espaço.

- Como onda é invisível, não pode ser localizada pois não tem massa.

- As imagens, ondas e partículas são descrições complementares de uma mesma realidade, estado do "ser" e do "vir-a-ser" que constitui um universo imprevisível e criativo, onde qualquer acontecimento ou evento é uma questão de pro- babilidade, o que passou a ser uma noção importante para a compreensão dos fenômenos da natureza. Em decorrência disso, nada no universo opera de modo linear, determinista, passo a passo e logicamente previsível.

- A criatividade é parte essencial da auto-organização da natureza, pois a matéria é criativa e viva.

Heisemberg descobriu que o comportamento das partículas é totalmente imprevisível e que esta "incerteza" não é conseqüência dos defeitos nos mecanismos de medida, mas sim da intervenção estrutural do sujeito no objeto observado, o que caracterizou o Princípio da Incerteza.

A partir desses fatos surgiu a necessidade de se olhar o mundo como:

- dinâmico, unificado, não hierarquizado, dialético, espiritual;

- um todo indiviso, no qual todas as partes do universo se fundem, incluindo o observador e seus instrumentos;

- uma totalidade em movimento constante;

- um fluxo de energia em processo de mudança onde nada é definitivo;

- um fluxo universal de eventos e processos;

- uma rede de relações e não uma entidade fragmentada.

O rigor matemático é questionado com o Teorema da Incompletude e com os teoremas sobre a impossibilidade de se encontrar dentro de um dado sistema formal, a prova de sua inconstância.

Também os avanços do conhecimento nos domínios da Microfísica, da Química e da Biologia, nos últimos anos do século XX, trazem reflexões epistemológicas de vulto e, principalmente, a Teoria das Estruturas Dissipativas de Hya Prigogine, que introduziu o conceito de Sistemas Abertos organizacionais, cuja evolução ocorre mediante trocas de energia com o meio ambiente, e o Princípio da Ordem Através de Flutuações que estabelece que nestes sistemas que funcionam às margens da estabilidade, a evolução explica-se por flutuações de energia que, em determinados momentos, nunca inteiramente previsíveis, desencadeiam espontaneamente reações que, por via de mecanismos não lineares, pressionam o sistema para além de um limite máximo de instabilidade e o conduzem a um novo estado macroscópico. Esta transformação irreversível e termodinâmica é o resultado da interação de processos microscópicos segundo uma lógica de auto-organização numa situação de não equilíbrio.

O ponto crítico em que a mínima flutuação de energia pode conduzir a um novo estado representa 
a potencialidade do sistema em ser atraído para um novo estado de menor entropia ${ }^{7}$.

Desse modo, a irreversibilidade nos Sistemas Abertos significa que esses são produtos da história.

A importância desse teorema está em sua vocação transdisciplinar, pois atravessa as várias ciências da natureza e as ciências sociais, provocando, juntamente com as outras condições, uma profunda reflexão sobre o conhecimento científico, que apresenta um declínio da hegemonia da causalidade e da legalidade, sendo a noção de lei substituída pelas noções de sistema, estrutura, modelo e processo.

Essas novas concepções da Física geraram uma profunda mudança na visão de mundo moderno, deixando o Universo de ser visto como uma máquina, composto de uma profissão de objetos distintos, para apresentar-se como um todo harmonioso e indivisível, uma rede de relações dinâmicas que inclui o observador e sua consciência. Esta percepção:

- pressupõe uma totalidade em movimento que tudo abarca, um fluxo de energia em constante mudança, um processo universal de eventos, onde nada é definitivo;

- reconhece a interdependência fundamental de todos os fenômenos e o perfeito entrosamento, dos indivíduos e das sociedades nos processos cíclicos da natureza;

- compreende a existência de uma consciência da unidade da vida, a interdependência de suas múltiplas manifestações, seus ciclos de mudanças e transformações;

- pressupõe um estado de inter-relação e independência essencial de todos os fenômenos físicos e antropossociais, em que cada evento é percebido em íntima relação com a totalidade e inserido num encadeamento que se desdobra no espaço e no tempo. Qualquer fato isolado é uma abstração. Para se conhecer um ser é preciso conhecer seu ecossistema e a teia de suas relações. A parte no todo e o todo presente nas partes;

- percebe a realidade em movimento, em que o passado se manifesta no presente e o futuro é aberto à possibilidade do vir a ser;

- compreende o movimento seqüencial de ordem-desordem-interação-organização-criação, do qual resultam múltiplas totalidades orgânicas. Nesse sentido, aponta a multidimensionalidade de tudo e o sujeito analítico como parte dessa realidade relacional. O todo é concebido mais do que as partes que o compõem, não sendo uma simples composição da somatória das partes e sim, uma totalidade nova, diferente de suas partes componentes. A conjuntura complexa confere a possibilidade, a condição e o sentido da existência de cada parte, indivíduo ou grupo;

- postula o construtivismo porque compreende o conhecimento como estando sempre em processo de construção, transformando-se mediante a ação do indivíduo no mundo, da ação do sujeito sobre o objeto;

- postula o interacionismo porque reconhece que sujeito e objeto são organismos vivos, ativos, abertos, em constante intercâmbio com o meio ambiente, mediante processos interativos indissociáveis e modificadores das relações sujeitoobjeto e sujeito-sujeito, a partir dos quais um modifica o outro e os sujeitos se modificam entre si;

- articula uma proposta sócio-cultural por compreender:

- que o "ser" se constrói na relação;

- que o conhecimento se produz na interação com o mundo físico, a partir do contato do indivíduo com a realidade, com os outros, incluindo aqui sua dimensão social, dialógica, inerente à própria construção do pensamento;

- que o diálogo faz um "ser datado e situado", que busca projetar-se, sair de si mesmo, transcender, a partir de sua ação e do mundo e da compreensão de sua própria natureza humana e divina.

- Permite que o homem vá além, se ultrapasse, se supere, entre em comunhão com a totalidade indivisível, compreendendo-se como parte integrante do universo, onde todas as coisas se tocam umas às outras, configurando a transcendência humana.

Nesta concepção, a realidade, por sua vez, é, constituída por processos dinâmicos que envolvem princípios integrativos e cooperativos.

Segundo Morin ${ }^{8}$, este paradigma comporta um princípio de complexidade que rompe, não só com a idéia de um meio rígido, mas também com as visões simplificadoras que isolam os seres de seu ambiente, separam a natureza da cultura e fragmentam os fenômenos, impedindo o desenvolvimento de uma consciência global.

Na ciência pós-moderna confluem sentidos vindos de nossas práticas locais, individuais, comunitá-

7. Grau de caos ou perturbação num sistema. Em termodinâmica, a entropia se relaciona com a parte da energia contida num sistema que pode ser convertida em trabalho utilizável.

8. Morin, E. O Método II: a vida da vida. 2 ed. Portugal : Publicações Europa-América, Biblioteca Universitária, 1980. 
rias, sociais e planetárias. Trata-se de interações de intertextualidades organizadas em torno de projetos locais de conhecimento indiviso. Um conhecimento temático, não disciplinar, que avança à medida que o objeto se amplia, procedendo pela diferenciação e pelo alastramento das raízes em busca de novas e mais variadas interfaces. É um conhecimento sobre as condições da possibilidade da ação humana projetada no mundo a partir de um espaço tempo local.

Cada método é uma linguagem e a realidade responde na língua em que é perguntada. Nesse sentido, o objeto é a continuação do sujeito, sendo os pressupostos metafísicos, os sistemas de crença, os juízos de valor, parte integrante da explicação científica da natureza e da sociedade, razão pela qual não há porque considerar a explicação científica como a única explicação possível da realidade.

A ciência moderna legou-nos um conhecimento funcional do mundo que alargou as nossas perspectivas de sobrevivência. Hoje não se trata de sobreviver, mas de saber viver. E, para isso, é necessária uma outra forma de conhecimento, um conhecimento compreensível e íntimo que não separe e fragmente, mas que nos una pessoalmente ao que estudamos e que interligue todos os fenômenos antropossociais.

\section{GESTÃo ACADÊMICA}

Estendendo-se essas questões à gestão acadêmica, uma Universidade que pretenda fazer frente às novas demandas do conhecimento, ampliando suas formas de atuação na sociedade, deve criar condições para o desenvolvimento das potencialidades de todos os sujeitos para compreender a realidade cultural, social, política e econômica do país com possibilidades à crítica e produção de conhecimentos, à intervenção, ética e à inserção cidadã dos futuros profissionais na sociedade. Para tal missão, deve privilegiar alguns princípios básicos:

- institucionalizar uma estrutura que possibilite uma gestão colegiada, através de um processo deliberativo democrático com competência para garantir a autonomia universitária acadêmica, política, administrativa e financeira possibilitando a construção de uma Universidade participativa e plural;

- implementar um projeto político-pedagógico que possibilite o alcance da missão universitária e que atenda as especificidades de cada área do conhecimento. A operacionalização deste projeto ocorre através da integração de elementos que compõem a estrutura quaternária da instituição, quais sejam: departamentos, unidades acadêmicas, centros (biomédico, tecnológico, educação e humanidades e ciências sociais) e administração central (sub-reitora de graduação, sub-reitora de pesquisa e pós-graduação, sub-reitora de cultura e extensão e superintendência de recursos humanos);

- nivelar as atividades-fim em uma estrutura que integre as ações de ensino, pesquisa e extensão em núcleos, incorporando os conhecimentos socializados no ensino às atividades de pesquisa e às ações comunitárias;

- aprimorar o sistema de planejamento acadêmico, assumindo-o como um processo dinâmico, flexível, possível de ajustes quando necessário, como por exemplo, a transição do regime seriado para o regime de inscrição em disciplina que, em alguns casos, coexistem;

- estabelecer uma relação adequada entre atividades-fim e atividades-meio (de natureza burocrático-administrativa) desburocratizando os serviços, de modo que os professores tenham condições favoráveis (recursos tecnológicos, humanos, ambientais e materiais) para organização e difusão de atividades de ensino, pesquisa e extensão;

- desenvolver uma política integrada de formação continuada para docentes, apoiando as diversas unidades acadêmicas na criação de espaços de reflexão permanente e contínuo sobre o próprio fazer, estimulando avaliações internas de suas atividades pedagógicas;

- integrar as unidades acadêmicas com as demandas sociais, viabilizando novos processos educacionais de ensino presencial e à distância;

- desenvolver um trabalho com ênfase no coletivo e na convivência humana, com base, por exemplo, na representação de professores, funcionários e estudantes nos colegiados superiores da Universidade;

- estimular e implementar atividades que intensifiquem o envolvimento e a co-responsabilidade dos alunos, ampliando o processo de ensino e aprendizagem;

- estimular maior articulação com as sociedades científicas;

- favorecer as relações da Universidade com o Estado e com a Sociedade Civil, como por exemplo, a implementação do Projeto de Educação Ambiental do Programa de Despoluição da Baía de Guanabara, através do convênio celebrado entre a Secretaria de Estado do Meio Ambiente e 
Desenvolvimento Sustentável (SEMADS)/Secretaria de Estado de Educação (SEE)/Fundação Estadual de Engenharia do Meio Ambiente (FEEMA) / Universidade do Estado do Rio de Janeiro (UERJ).

\section{COMPETÊNCIAS MÍNIMAS PARA O ENSINO DA ODONTOLOGIA}

A formação de sujeitos capazes de criar, em cooperação com os demais, uma ordem social na qual todos possam viver com dignidade, a partir de um projeto de sociedade como um todo, caracteriza-se pelo desenvolvimento de determinadas competências mínimas que, no caso específico do ensino da Odontologia, pressupõem:

- a construção de um profissional generalista competente (dotado de visão técnico-científica), com uma visão da complexidade de mundo contemporâneo, apto a trabalhar em equipe multiprofissional (visão sócio-política) com a promoção da saúde e a melhoria da qualidade de vida das populações;

- o estabelecimento de um contraponto com a Odontologia tradicional, que forma um profissional tecnicista, sem compromisso com a sociedade;

- a implementação de planejamentos integrados participativos, que incorporem a discussão das diretrizes curriculares estabelecidas pelos docentes, discentes, técnicos administrativos e usuários;

- a implantação de novas estratégias de ensino que levem em conta o projeto político-pedagógico da Instituição de Ensino Superior;
- a incorporação da interdisciplinaridade como uma premissa básica e como pressuposto da inclusão de conhecimento sumarísticos e da prática da clínica integrada, que exige uma reformulação da atuação docente/discente;

- a melhoria das condições de saúde bucal da população, a partir do conhecimento do seu perfil epidemiológico.

Para desenvolver a faculdade de mobilizar um conjunto de recursos cognitivos (saberes, capacidades, informações, etc.) para solucionar uma série de situações encontradas no mundo contemporâneo, inúmeros educadores apontam como competências necessárias para o ensino no século XXI o trabalho em equipe e o envolvimento dos alunos em suas aprendizagens e em seu trabalho (Perrenoud); organização do currículo por projetos (Hermández); e a necessidade de manter-se atualizado sobre as novas metodologias de ensino e o desenvolvimento de práticas pedagógicas eficientes (Nóvoa). Tais competências pretendem nortear a participação produtiva e a inserção social do ser humano no século XXI, com a formação de um sujeito com capacidade de compreender e atuar no seu entorno social, analisando, sintetizando e interpretando dados, fatos e situações, além de perceber criticamente os meios de comunicações e saber localizar, acessar e usar melhor a informação acumulada com vistas a planejar, de forma integrada e com responsabilidade ético-solidária, ações que tragam soluções para as problemáticas identificadas. 